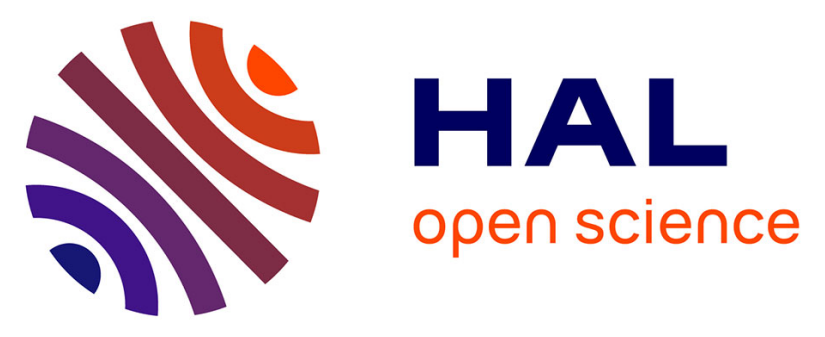

\title{
The diagnostic value of hyperammonaemia induced by the non-ischaemic forearm exercise test
}

Jean-Yves Hogrel, Jorien B E Janssen, Isabelle Ledoux, Gwenn Ollivier, Anthony Béhin, Tanya Stojkovic, Bruno Eymard, Nicol C Voermans, Pascal Laforet

\section{To cite this version:}

Jean-Yves Hogrel, Jorien B E Janssen, Isabelle Ledoux, Gwenn Ollivier, Anthony Béhin, et al.. The diagnostic value of hyperammonaemia induced by the non-ischaemic forearm exercise test. Journal of Clinical Pathology, 2017, 70 (10), pp.896 - 898. 10.1136/jclinpath-2017-204324 . hal-01618833

\section{HAL Id: hal-01618833 \\ https://hal.sorbonne-universite.fr/hal-01618833}

Submitted on 18 Oct 2017

HAL is a multi-disciplinary open access archive for the deposit and dissemination of scientific research documents, whether they are published or not. The documents may come from teaching and research institutions in France or abroad, or from public or private research centers.
L'archive ouverte pluridisciplinaire HAL, est destinée au dépôt et à la diffusion de documents scientifiques de niveau recherche, publiés ou non, émanant des établissements d'enseignement et de recherche français ou étrangers, des laboratoires publics ou privés. 
The diagnostic value of hyperammonemia induced by the non-ischemic forearm exercise test

Jean-Yves Hogrel ${ }^{1 *}$, Jorien B.E. Janssen ${ }^{2 *}$, Isabelle Ledoux ${ }^{1}$, Gwenn Ollivier ${ }^{1}$, Anthony

Béhin $^{3}$, Tanya Stojkovic ${ }^{3}$, Bruno Eymard ${ }^{3}$, Nicol C. Voermans ${ }^{2}$, Pascal Laforet ${ }^{3}$

${ }^{1}$ Institute of Myology, Pitié-Salpêtrière Hospital, Paris, France

${ }^{2}$ Department of Neurology, Radboud University Medical Centre, Nijmegen, The Netherlands

${ }^{3}$ Paris-Est Neuromuscular Center, Institute of Myology, Pitié-Salpêtrière Hospital, Assistance

Publique Hôpitaux de Paris, France

*These authors contributed equally to this work

Correspondance to Jean-Yves Hogrel, Institut de Myologie, Groupe Hospitalier Pitié-

Salpêtrière, 75651 Paris Cedex 13, France.

Phone: +33142165880; Fax: +33142165881

E-mail address: jy.hogrel@institut-myologie.org

Word count: 1410

Keywords: Hyperammonemia; Diagnostic test assessment; Metabolic myopathy;

Glycogenosis; Muscle disease 


\begin{abstract}
Aims The non-ischemic forearm exercise test (NIFET) is used as a diagnostic tool for the screening of patients with exercise intolerance and for the diagnosis of various metabolic muscle disorders. The production of lactate and ammonia are generally analyzed to guide the diagnosis. The aim of this retrospective study was to determine the level of ammonia rise, which can be suggestive of a muscle disease.
\end{abstract}

Methods: This retrospective study involved 1440 patients who underwent NIFET. The clinical files of the patients with hyperammonemia were methodically studied. Normal values were derived from 60 healthy controls.

Results: 110 patients with hyperammonemia were detected. They were classified as either having mild (between 94 and $141 \mu \mathrm{mol} / \mathrm{L}$ ) or severe (more than $141 \mu \mathrm{mol} / \mathrm{L}$ ) hyperammonemia. Their diagnosis were studied with respect to the increase in lactate induced by the NIFET.

Conclusions: Severe post-exercise hyperammonemia, even in the presence of a normal lactate response, is strongly suggestive of a muscle glycogen storage disease. Mild hyperammonemia in the absence of other abnormalities is most likely non-specific and not indicative of a muscle disease. 


\section{INTRODUCTION}

The non-ischemic forearm exercise test (NIFET, also known as the Grip Test) is often used as a screening test for metabolic myopathies in patients with exercise intolerance, exerciseinduced cramps and myalgia. It has been proven to be a very sensitive and specific tool for the detection of McArdle's disease (glycogen storage disease type V: GSDV). The combination of a blunted increase in lactate $(\mathrm{La})(\Delta \mathrm{La}<0.8 \mathrm{mmol} / \mathrm{l})$ and large increase in ammonia $(\mathrm{NH} 3)$ $(\Delta \mathrm{NH} 3>40 \mu \mathrm{mol} / \mathrm{l})$ results in a sensitivity and a specificity of $100 \%$ and $99.7 \%$ respectively for this disease ${ }^{1}$. However the same biochemical profile may occasionally be observed in patients with glycogenosis type III. Another subgroup of patients presents with a high ammonia response along with a normal or mildly blunted lactate response, and the clinical relevance of this isolated hyperammonemia during the NIFET is largely unknown ${ }^{1-5}$. The basic principles of ammonia production in muscle have already been well described ${ }^{6}$. During short intense exercise, ammonia is produced predominantly by the deamination of adenosine monophosphate (AMP) into inosine monophosphate (IMP) by the enzyme adenylate deaminase in the purine nucleotide cycle. AMP is itself produced by ATP (adenosine triphosphate) and ADP (adenosine diphosphate) hydrolysis during energy production for muscle contraction. In glycogen storage diseases, hyperammonemia is most likely caused by an exaggerated AMP deamination due to deregulation of adenine nucleotides, which causes exercise intolerance due to a critical shortage of ATP ${ }^{4}$. However the level of production of ammonia which would be indicative of a muscle disease remains to be determined.

The primary aim of this study was to systematically analyse the clinical features and the diagnostic results of patients who showed a high ammonia response during the NIFET. In addition, the extent of hyperammonemia was analyzed to determine if it could be used as a screening tool to identify metabolic myopathies. 


\section{MATERIALS AND METHODS}

All of the patients who performed NIFET between 1999 and $2015(n=1440)$ at the Institute of Myology (Pitié-Salpêtrière Hospital, Paris) were included in this study. Many of them also underwent several additional investigations including neurological examination, cardiorespiratory evaluation, nerve conduction studies and electromyography (ENMG), muscle imaging with either CT-scan or MRI (magnetic resonance imaging), muscle biopsy with immunochemistry, western-blot, respiratory chain analysis, and molecular analysis. Normal values were derived from 60 healthy controls aged between 23 and 58 years (see Table 3 in Hogrel et al., $2015^{1}$ ).

The NIFET protocol has previously been described ${ }^{7}$. Briefly, it consists of a 30 -second isometric grip contraction sustained at $70 \%$ of the maximal grip strength after which blood samples are taken at 1, 2, 3, 4, 6 and 10 minutes. Lactate and ammonia are measured according to standardized procedures (see Hogrel et al., $2015^{1}$ ) and compared with baseline values. In controls $(n=60)$, the mean increase in the level of ammonia between resting and peak values was $42.8 \pm 25.9 \mu \mathrm{mol} / \mathrm{L}$. After testing the distribution in the levels of ammonia rise for normality (Kolmogorov-Smirnov test, $\mathrm{p}>0.1$ ), hyperammonemia was defined as $\Delta \mathrm{NH} 3 \geq 94 \mu \mathrm{mol} / \mathrm{L}$ corresponding to the upper reference limit (URL) computed as 2 standard deviations above the mean of the control population. Computing this threshold from log transformed data yielded the same value.

All patients with hyperammonemia were selected and classified according to their increase in lactate using the previously described threshold ${ }^{1}: \Delta \mathrm{La} \leq 0.8 \mathrm{mmol} / \mathrm{L}$ and $\Delta \mathrm{La}>0.8 \mathrm{mmol} / \mathrm{L}$. In patients with unexplained hyperammonemia, we reviewed the medical files for data about medical history, neurological examination, ENMG, muscle imaging, muscle biopsy, molecular analysis and possible subsequent diagnosis. Next, if considered appropriate, 
additional tests were performed by the metabolic neuromuscular specialist in line with our current local diagnostic guidelines. These tests included enzyme assays for glycogenolysis/glycolysis defects (2 patients), respiratory chain analysis (3 patients), genetic analysis of the mitochondrial DNA (5 patients), gene sequencing panels ( 8 patients) and immunohistochemistry/immunoblotting on muscle biopsy (1 patient).

Subsequently we assessed the NIFET results and final diagnosis of all patients with hyperammonemia to determine if a high ammonia response could be used as a screening tool to detect unusual metabolic myopathies.

\section{RESULTS}

Out of 1440 patients, 110 patients $(7.6 \%)$ with hyperammonemia $(\Delta \mathrm{NH} 3 \geq 94 \mu \mathrm{mol} / \mathrm{L})$ were identified (Figure 1). All patients with a small increase in lactate $(\Delta \mathrm{La} \leq 0.8 \mathrm{mmol} / \mathrm{L})$ were diagnosed with either McArdle disease (GSDV) (n=32) or a debranching enzyme deficiency (GSDIII) $(\mathrm{n}=1)$. Of the patients with a normal increase in lactate $(\Delta \mathrm{La}>0.8 \mathrm{mmol} / \mathrm{L} ; \mathrm{n}=77)$, only eight were diagnosed at the beginning of the retrospective analyses with GSDIII $(n=4)$, phosphorylase b kinase deficiency (GSDIX) ( $\mathrm{n}=1)$, phosphoglucomutase 1 deficiency (GSDXIV) (n=2) and mitochondrial myopathy related to MELAS (mitochondrial encephalomyopathy, lactate acidosis and stroke-like episodes) mutation ( $\mathrm{n}=1)$. Additional diagnostic tests have so far resulted in a definitive diagnosis for five additional patients: GSDIII (n=1), GSDIX (n=1), LGMD2B (limb girdle muscular dystrophy type 2B) $(n=1)$, LGMD2I (limb girdle muscular dystrophy type 2I) (n=1) and RYRl-related myopathy (RYR1: ryanodine receptor 1$)(n=1)$. Ammonia levels at rest were not significantly different between controls $(24.3 \pm 12.0 \mu \mathrm{mol} / \mathrm{L})$ and patients $(26.3 \pm 11.9 \mu \mathrm{mol} / \mathrm{L})$ (unpaired t-test, $\mathrm{p}=0.304)$. Subsequently we divided the cohort of patients with hyperammonemia into two sub-groups: the first with mild hyperammonemia (between 1 and 1.5 URL: 94 to $141 \mu \mathrm{mol} / \mathrm{L} ; \mathrm{n}=72$ ); and a 
second group with severe hyperammonemia (higher than 1.5 URL: >141 $\mu \mathrm{mol} / \mathrm{L} ; \mathrm{n}=38$ ). All but one of the patients in the latter group (with a $R Y R 1$ mutation) were diagnosed with a glycogenosis (82\%) (Figure 2). Among the six remaining undiagnosed patients, three presented an exaggerated lactate response. Hence, most of the patients without or with other diagnoses were in the mild hyperammonemia group.

\section{DISCUSSION}

The main findings of this retrospective study on ammonia response during the NIFET in a large patient cohort referred for exercise intolerance are: 1) Severe post-exercise hyperammonemia $(\mathrm{NH} 3>141 \mu \mathrm{mol} / \mathrm{L})$ points towards a diagnosis of glycogenosis in more than $80 \%$ of the patients, even when the production of lactate remains within the normal range; 2) Mild post-exercise hyperammonemia $(94<\Delta \mathrm{NH} 3<141 \mu \mathrm{mol} / \mathrm{L})$ is a major hallmark of muscle glycogenosis especially when the lactate production is decreased; 3) Mild hyperammonemia $(94<\Delta \mathrm{NH} 3<141 \mu \mathrm{mol} / \mathrm{L})$ associated with normal lactate increase, and without abnormalities of conventional diagnostic tests (muscle imaging, ENMG and/or muscle biopsy) is likely to be physiological.

Future diagnostic studies should not only take into account the absolute increase in ammonia $(\Delta \mathrm{NH} 3)$, but could also consider the NH3 peak alone or the area under the concentration-time curve to define hyperammonemia. Furthermore, in the group of patients with mild hyperammonemia (94-141 $\mu \mathrm{mol} / \mathrm{L})$, many had no abnormalities on other complementary investigations. We therefore suggest that the cut-off value for hyperammonemia should be higher than $94 \mu \mathrm{mol} / 1$, while in our study we used $141 \mu \mathrm{mol} / \mathrm{l}$.

A limitation of this study is its retrospective nature with some of the patient data being up to 15 years old. Thus, it was sometimes impossible to obtain information regarding the clinical course to confirm that no new symptoms had occurred, the molecular analysis or possible 
diagnosis confirmed later during the follow-up in another medical center. Therefore we cannot ascertain that our conclusion concerning the non-specificity of hyperammonemia is accurate. The growing development of exome sequencing technology in the near future should allow us to look for new genes implicated in as yet unknown metabolic pathways involved in hyperammonemia.

Severe hyperammonemia at NIFET $(\Delta \mathrm{NH} 3>141 \mu \mathrm{mol} / \mathrm{L})$ should always bring one's attention toward a diagnosis of muscle glycogenosis, and genetic testing of PYGM (gene encoding myophosphorylase) should be performed first. Assessment of blood debranching enzyme activity should be done if the patient also presents with hepatomegaly and/or hypoglycaemic episodes. This study also showed that mild hyperammonemia ( $\triangle \mathrm{NH} 3$ between 94 and 141 $\mu \mathrm{mol} / \mathrm{L}$ ) may occur in a few patients with muscular dystrophies and mitochondrial myopathy but this anomaly is probably coincidental as it was also observed in 4 of the 60 control subjects (unpublished data).

In conclusion, severe post-exercise hyperammonemia $(\Delta \mathrm{NH} 3>141 \mu \mathrm{mol} / \mathrm{L})$ even in the presence of a normal lactate response, is strongly suggestive of a muscle glycogenosis as no other metabolic myopathy could be identified so far. Mild hyperammonemia in the absence of abnormalities on other tests is most likely non-specific and not indicative of a disease.

Acknowledgements We are grateful to Simone Birnbaum and Gillian Butler-Browne for thorough reading of the manuscript and improvement in the text.

Study funding J.B.E. Janssen was funded by Prinses Beatrix Spierfonds. This study was funded in part by the Association Française contre les Myopathies.

Contributors JYH and PL designed the study. AB, TS, BE, PL and NCV gathered and interpreted the clinical data. JYH, IL and GO collected the exercise data. JYH and JBEJ 
analyzed the data and drafted the paper. All authors read, revised and approved the final manuscript.

Competing interests None declared 


\section{References}

1. Hogrel JY, van den Bogaart F, Ledoux I, et al. Diagnostic power of the non-ischaemic forearm exercise test in detecting glycogenosis type V. European journal of neurology 2015;22(6):933-40.

2. Coleman RA, Stajich JM, Pact VW, et al. The ischemic exercise test in normal adults and in patients with weakness and cramps. Muscle \& nerve 1986;9(3):216-21.

3. Fishbein WN, Foellmer JW, Davis JI. Medical implications of the lactate and ammonia relationship in anaerobic exercise. International journal of sports medicine 1990;11 Suppl 2:S91-100.

4. Mineo I, Kono N, Shimizu T, et al. Excess purine degradation in exercising muscles of patients with glycogen storage disease types V and VII. The Journal of clinical investigation 1985;76(2):556-60.

5. Stojkovic T, Vissing J, Petit F, et al. Muscle glycogenosis due to phosphoglucomutase 1 deficiency. The New England journal of medicine 2009;361(4):425-7.

6. Dulaney E, Katirji B. Forearm exercise testing. In: Katirji B, Kaminski H, Ruff RL, eds. Neuromuscular disorders in clinical practice. Second ed. New-York: Springer 2014:79-88. 7. Hogrel JY, Laforet P, Ben Yaou R, et al. A non-ischemic forearm exercise test for the screening of patients with exercise intolerance. Neurology 2001;56(12):1733-8. 


\section{Figure captions}

Figure 1 - Diagnostic flowchart of the hyperammonemia cohort $(\Delta \mathrm{NH} 3>94 \mu \mathrm{mol} / \mathrm{L})$. From the 1440 patients in the database, 110 were identified as having hyperammonemia. This population was divided in two groups based on the lactate response after the non-ischemic forearm exercise test. All patients with a small increase in lactate $(\Delta \mathrm{La} \leq 0.8 \mathrm{mmol} / \mathrm{L})$ were diagnosed with either a GSDV or a GSDIII. Of the patients with a normal increase in lactate ( $\Delta \mathrm{La}>0.8 \mathrm{mmol} / \mathrm{L}$ ), only 13/77 have been diagnosed. (GSD: glycogen storage disease; mito: mitochondriopathy; RYR1: RYR1-related myopathy; LGMD: limb girdle muscular dystrophy)

Figure 2 - Diagnostic flowchart for patients presenting with severe hyperammonemia $(\Delta \mathrm{NH} 3>141 \mu \mathrm{mol} / \mathrm{L})$. From the 1440 patients in the database, 38 were identified as having severe hyperammonemia (more than 1.5 the upper reference limit). In this later group, $82 \%$ were diagnosed with a glycogen storage disease. (GSD: glycogen storage disease; mito: mitochondriopathy; RYR1: RYR1-related myopathy) 
Figure 1

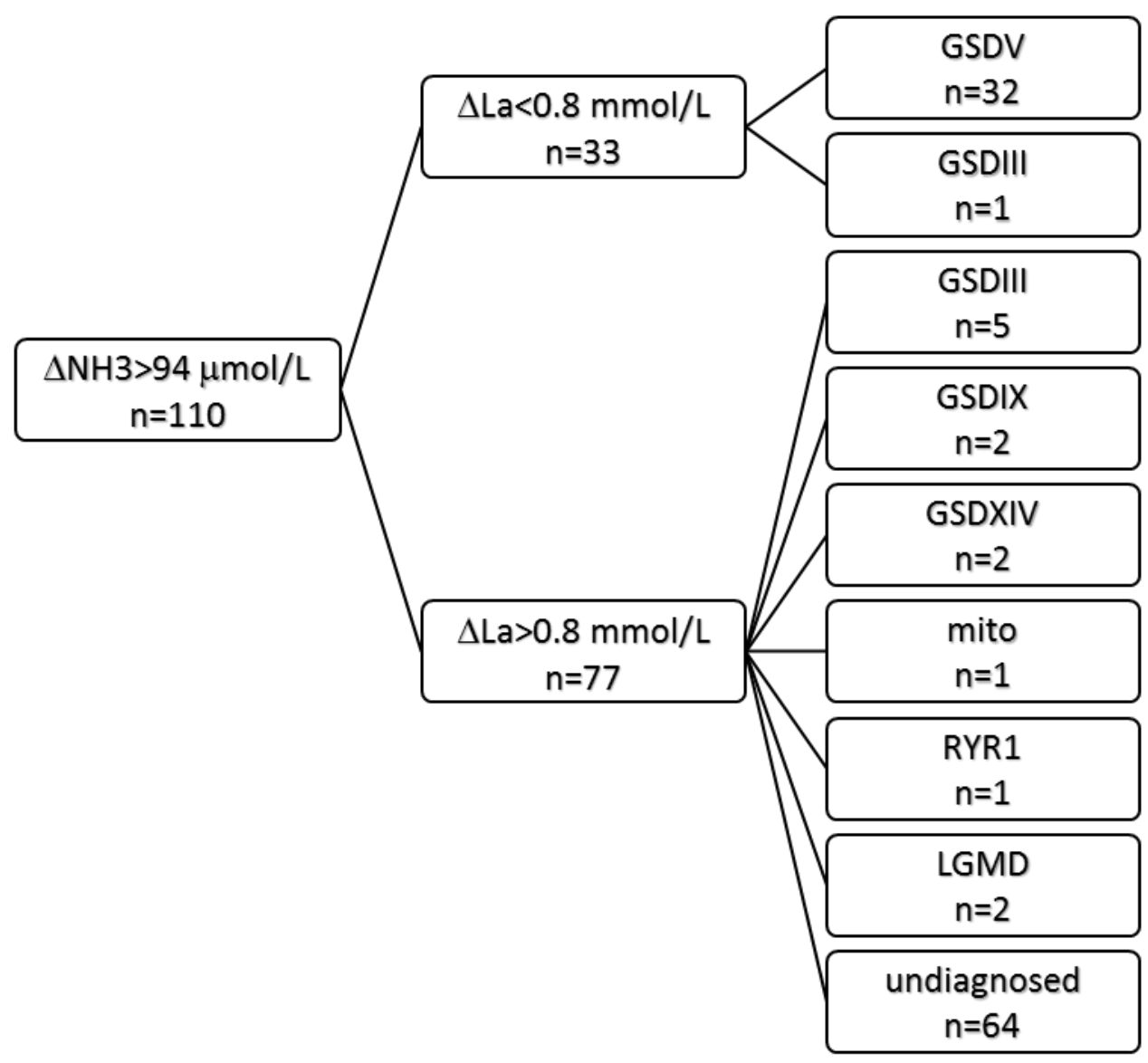


Figure 2

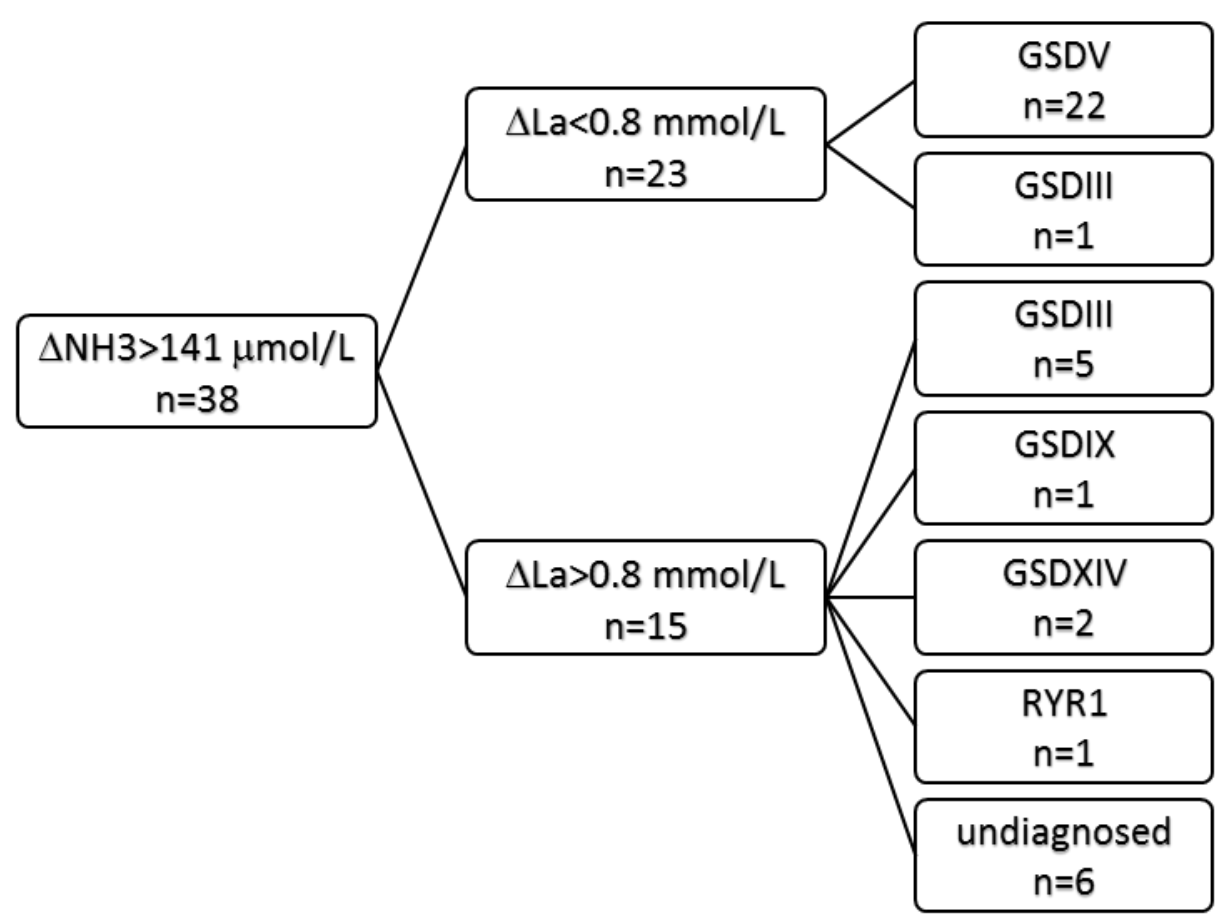

